\title{
Heat Transport Modeling in an Aquifer Downgradient a Municipal Solid Waste Landfill in Italy
}

\author{
Rajandrea Sethi, Antonio Di Molfetta \\ DITAG - Dipartimento del Territorio, dell'Ambiente e delle Geotecnologie \\ Politecnico di Torino - C.so Duca degli Abruzzi 24, 10129 - Torino, Italy
}

\begin{abstract}
Heat generation inside municipal solid waste (MSW) landfills is due to aerobic and anaerobic exothermic reactions occurring inside the waste. The result of heat generation and transport inside sanitary landfill leads to a temperature field that varies from mesophylic range (optimum at $30-40{ }^{\circ} \mathrm{C}$ ) to thermophylic range (optimum at $50-60{ }^{\circ} \mathrm{C}$ ). Due to high temperatures at the bottom of the landfill, liner systems can be severely damaged. The increment in convective and conductive heat transport could lead to an increase of the temperature in the surrounding geological layers and in the underlying aquifer. Hydrodynamic thermodispersion and convection are the most important mechanisms of heat transport in saturated porous medium with a moving fluid such as aquifer systems. The aim of the study is to model and investigate the origin of a thermal anomaly in the aquifer underneath a municipal landfill in the North of Italy. In order to model the system a detailed experimental analysis was conducted inside the landfill, measuring the temperature of the biogas and leachate, and in the aquifer system measuring the temperature in monitoring wells and conducting a constant rate pumping test. Heat transport model has been exploited using the analogy between heat and mass transport in porous media. The model showed that the thermal anomaly is due to convective and conductive heat transport from the landfill to the aquifer.
\end{abstract}

Keywords: municipal solid waste landfill, groundwater engineering, aquifer, heat transport

\section{INTRODUCTION}

Sanitary landfills are characterized by heat generation due to exothermic aerobic and anaerobic reactions occurring inside the waste.

The aerobic reactions start soon after the dumping of the waste on the top of the landfill. These processes are strongly exothermic and the heat generation is proportional to the oxygen consumption. Measurements of waste temperatures in MSW landfills indicate a temperature peak immediately after the deposit of the refuse, followed by a decrease and stabilization. A thermal balance shows that more than $80 \%$ of the heat produced during the landfilling is evolved by aerobic waste decomposition.

The addition of a new fresh layer insulates the waste reducing the oxygen penetration process. After a lagphase of about six months - one year, during which no reaction occurs, anaerobic methanogenesis reactions take place. During this phase heat generation is a result of the enthalpy of the organic matter degradation reactions occurring inside the waste. Temperature profile inside a landfill is not only the result of heat generation process but also of heat transport inside and across the borders of the landfill. Heat transport mechanisms could be divided into:

- convection: heat transport depends on mass transport of biogas, vapor and leachate;
- conduction and radiation: mechanisms independent from mass movements;

- heat exchange across the borders of the landfill: heat transport across top, bottom and sides of the landfill.

The result of heat generation and transport inside sanitary landfill leads to a temperature field that varies from mesophylic range (optimum at $30-40^{\circ} \mathrm{C}$ ) to thermophylic range (optimum at $50-60^{\circ} \mathrm{C}$ ). The temperature on the surface of the landfill is more or less the same as outside, rises to its maximum in the middle and decreases at the base of the landfill (Fig. 1).

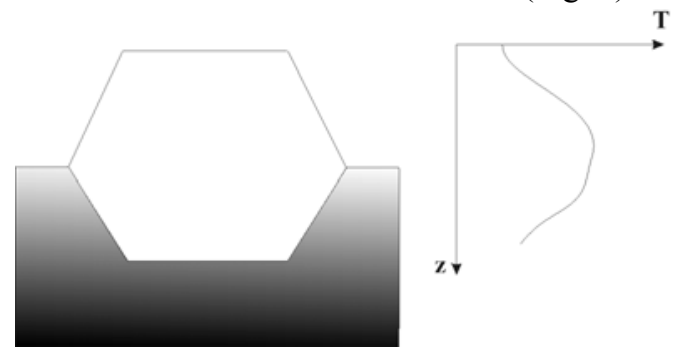

Fig. 1: Temperature profile inside a MSW landfill

Heat generation and transport models inside municipal solid waste disposals are monodimensional and are developed mainly to simulate the temperature influence on biogas production ${ }^{[1,2,3,4,5]}$.

Corresponding Author: Rajandrea Sethi, DITAG (Dipartimento del Territorio, dell'Ambiente e delle Geotecnologie) Politecnico di Torino, c.so Duca degli Abruzzi 24, 10129 - Torino, Italy 
Several investigations ${ }^{[3]}$ report temperature of more than $50{ }^{\circ} \mathrm{C}$ at the base of MSW landfills. Due to high temperatures the liner systems can be severely damaged. The increment in convective and conductive heat transport could lead to an increase of the temperature in the surrounding geological layers and in the underlying aquifer.

Heat transport inside aquifer systems is due to convection and hydrodynamic thermodispersion and convection are the most important mechanisms of heat transport in saturated porous medium with a moving fluid such as aquifer systems.

Fourier's law ${ }^{[6]}$ describes conductive transport in a solid or a liquid by a linear expression relating the heat flux to the temperature gradient. When dealing with fluids within solids, it is sometimes necessary to introduce an effective thermal conductivity. Under the hypothesis of thermal equilibrium between solid and liquid phases, the generalized Fourier's law becomes:

$$
J_{i}=-\lambda^{c o n d} \frac{\partial T}{\partial x_{i}}
$$

with $J_{i}$ the heat flux vector, $\lambda^{\text {cond }}$ the effective thermal conductivity accounting the properties of both fluid and solid phases (e.g. $\left.\lambda^{\text {cond }}=n \lambda^{f}+(1-n) \lambda^{s}\right), n$ the total porosity.

If the fluid is in motion, a thermal dispersion effect is generated by the heterogeneity in the flow field. Thermal dispersion is a microscopic dispersal of heat that has the same macroscopic effect as an increase in the thermal conductivity ${ }^{[7]}$ :

$$
J_{i}=\left(\lambda^{c o n d} \delta_{i j}+\lambda_{i j}^{d i s p}\right) \frac{\partial T}{\partial x_{j}}
$$

where $\lambda_{i j}^{d i s p}$ is the thermodispersion tensor depending on the fluid velocity:

$$
\lambda_{i j}^{\text {disp }}=\rho^{f} c^{f} n\left[\beta_{T} V \delta_{i j}+\left(\beta_{L}-\beta_{T}\right) \frac{v_{i} v_{j}}{V}\right], \rho^{f} c^{f} \text { is the }
$$

volumetric heat capacity of water, $n$ the total porosity, $\beta_{L}$ and $\beta_{T}$ the longitudinal and transverse thermodispersivity, $V$ the absolute velocity, $v_{i}$ the velocity vector.

Convection is an energy transport mechanism due to fluid motion inside the medium. When the flow field is caused by external forces, the transport is said to occur by forced convection. Free or natural convection, instead, occurs when the movement of water is due to density variations caused by temperature gradients. When natural convection dominates, the velocity field and the energy field (temperature) are interdependent, and the equations must be solved iteratively.
The equation for groundwater motion may be described in terms of two driving forces, fluid pressure changes and buoyancy, and is of the form:

$$
v_{i}=-\frac{k_{i j}}{n \mu}\left(\frac{\partial p}{\partial x_{j}}+\rho g_{j}\right)
$$

where $\mathrm{k}_{\mathrm{ij}}$ is the aquifer permeability tensor, $\mu$ the dynamic viscosity (temperature dependent), $\mathrm{p}$ the pressure, $\rho$ the water density (temperature dependent). From all the above mentioned mechanisms, the principle of heat conservation, could be derived:

$$
\frac{\partial}{\partial t}\left(\rho^{\prime} c^{\prime} T\right)=-\frac{\partial}{\partial x_{i}}\left(n v_{i} \rho^{f} c^{f} T\right)+\frac{\partial}{\partial x_{i}}\left(\lambda_{i j} \frac{\partial T}{\partial x_{j}}\right)+Q_{\rho} T
$$

with $\rho^{f} c^{f}$ the volumetric heat capacity of water, $\rho^{\prime} c^{\prime}$ the volumetric heat capacity of the porous medium $\rho^{\prime} c^{\prime}=n \rho^{f} c^{f}+(1-n) \rho^{s} c^{s}, \mathrm{n}$ the total porosity, $\mathrm{Q}_{\mathrm{p}} \mathrm{T}$ an heat source term. The second member of the above equation include a convective heat transport term, a thermodispersion term and a heat source term. This equation is analogous to the mass balance equation in solute transport problems.

As said before, due to the dependence of fluid density and viscosity on temperature, the flux and thermal equations are said to be coupled and the PDE system must be solved iteratively.

The most important commercial computer models to simulate coupled flux and heat transport in aquifer are FEFLOW ${ }^{[7]}$, HOTWTR, HST3D, SWIFT 98, SUTRA.

\section{MATERIALS AND METHODS}

The studied MSW landfill is located in the North of Italy and is made of several cells cultivated since 1984 . The bottom impermeable layer is different from cell to cell depending on the year of construction.

Physical and chemical groundwater parameters of the aquifer underneath the landfill are monitored in 13 piezometric wells placed around the landfill. Some past measurements revealed a thermal anomaly in the aquifer downgradient $1 \mathrm{~A}$ and $2 \mathrm{~A}$ cells ${ }^{[8]}$. In order to give a better quantification of the problem a very detailed experimental analysis was conducted, both inside and outside the landfill: several temperature measurements were conducted inside the aquifer, in the waste, in the biogas and in the leachate wells.

The temperatures in the aquifer were periodically surveyed in the piezometric wells to evaluate the variations of temperature versus time.

The study revealed a thermal anomaly of $4^{\circ} \mathrm{C}$ downgradient cells $1 \mathrm{~A}$ and $2 \mathrm{~A}$ of the landfill (Fig. 2). 


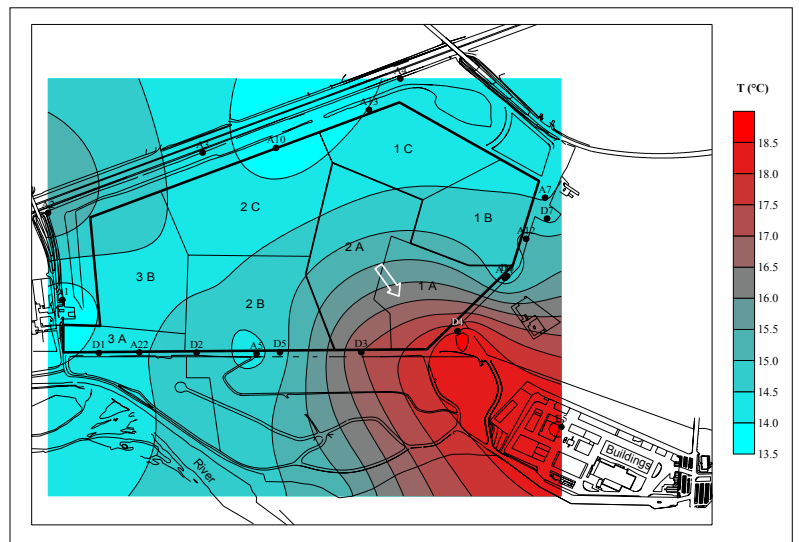

Fig. 2:Experimental reconstruction of the groundwater temperature field.

In the hottest spots the water reaches $18.5^{\circ} \mathrm{C}$ versus $14.5^{\circ} \mathrm{C}$ of the background area. Some pumping tests were conducted in order to evaluate the entity of the anomaly. Well D4 and the surrounding piezometers were provided with multiparametric probes to measure and register water level, temperature, $\mathrm{pH}$ and chemical conductivity versus time. During the pumping phase a temperature and chemical conductivity increase was observed (Fig. 3). Instead, during the recovery phase a sudden decrease and than a stabilization of temperature and a decrease of conductivity were reported. The explanation of this phenomenon should be searched in the interception of water with different thermal and chemical properties probably due to mixing with leachate coming from the landfill.

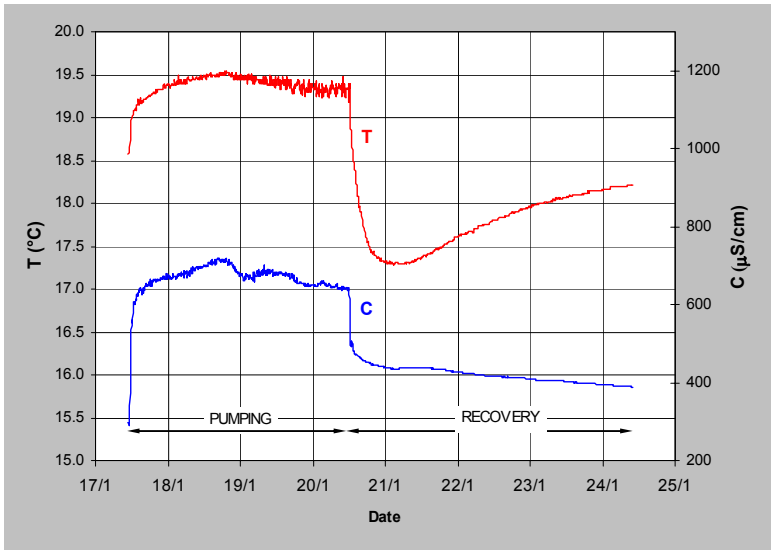

Fig. 3: Temperature and chemical conductivity measurements during pumping test in D4 well.

To understand the origin of the thermal anomaly some measurement were performed inside the landfill (i.e in the leachate and biogas wells).
The temperature of the leachate (Table 1), in the collection points located outside the landfill, could provide important informations about the temperature of the bottom part of the landfill. The range of temperature measured is $11-27^{\circ} \mathrm{C}$. The highest value of temperature wasn't measured in 1A cell but in 1B. Temperature measurement in biogas wells revealed an high horizontal variation from well to well, but a small vertical temperature gradient. The measured temperatures, belonging to mesophylic or thermophylic range, were variable from $30^{\circ} \mathrm{C}$ to $55^{\circ} \mathrm{C}$. Again the hottest zone was outside $1 \mathrm{~A}$ or $2 \mathrm{~A}$ cells.

\begin{tabular}{ccc} 
Table 1: Temperature measurements in leachate wells \\
\hline Cell & $\begin{array}{c}12 / 02 / 2000 \\
\mathrm{~T}\left({ }^{\circ} \mathrm{C}\right)\end{array}$ & $\begin{array}{c}22 / 03 / 2000 \\
\mathrm{~T}\left({ }^{\circ} \mathrm{C}\right)\end{array}$ \\
\hline 1A & 21.2 & 22.6 \\
2A & 22.0 & 19.4 \\
2B & 14.3 & 15.3 \\
3A-1 & 13.7 & 15.4 \\
3A-2 & - & 14.6 \\
2C-1 & 10.8 & 15.5 \\
2C-2 & 19.7 & 16.4 \\
1B-1 & 25.0 & 26.9 \\
1B-2 & - & 21.0 \\
1C-1 & 15.0 & 24.7 \\
1C-2 & 10.6 & 20.8 \\
\hline
\end{tabular}

At the end of the investigation, no evidences were found to prove that temperature in $1 \mathrm{~A}$ or $2 \mathrm{~A}$ cell were higher than elsewhere.

The only reason that could explain the high temperature in groundwater is an high conductive or convective heat transport from the landfill towards the underlying aquifer. The hypothesis of an high conductiveconvective transport is supported by a poor natural and artificial impermeabilization under the two cells; moreover the rising of chemical conductivity during pumping could be an evidence of convective heat transport.

In presence of small thermal gradients buoyancy effects could be neglected and simpler models could be used as discussed in the following paragraph.

Heat transport model: An heat transport model was developed in order to search the best heat boundary condition to reproduce the thermal anomaly in the aquifer, the simulation was conducted using the contaminant transport model MT3DMS ${ }^{[9]}$.

The use of a solute transport model to simulate heat transport was possible exploiting the analogy between the differential equations that regulate the two problems. The heat balance equation could be written as:

$$
\frac{\partial T}{\partial t}+\frac{v_{i}}{R_{T}} \frac{\partial T}{\partial x_{i}}-\frac{1}{R_{T}} \frac{\partial}{\partial x_{i}}\left(\Lambda_{i j} \frac{\partial T}{\partial x_{j}}\right)=\frac{Q_{\rho} T}{n R_{T}}
$$


where $R_{T}=\frac{\rho^{\prime} c^{\prime}}{n \rho_{f} c_{f}} \quad$ is the thermal retardation coefficient and $\Lambda_{i j}=\frac{\lambda_{i j}}{n \rho_{f} c_{f}} \quad$ the corrected thermodispersion tensor. The retardation factor accounts of heat transport processes occurring both in water and in solid phases unlike contaminant transport. The small thermal gradients in the aquifer permitted the decoupling of the flow and heat transport equations. Density and viscosity variations with temperature were considered negligible and also the buoyancy term in momentum equation. In this way fluid motion is only due to forced convection.

The model was first calibrated in order to reproduce the piezometric surface using the parameters reported in Table 2. In a second time the most representative heat transport boundary conditions to reproduce the thermal field inside the aquifer were searched. Two scenarios were simulated using the following heat boundary conditions:

- in the first we looked for the constant temperature, in the groundwater under $1 \mathrm{~A}$ and $2 \mathrm{~A}$ cells, to reproduce the thermal anomaly in the aquifer. These temperature are $18.5^{\circ} \mathrm{C}$ under the $1 \mathrm{~A}$ cell and $17{ }^{\circ} \mathrm{C}$ under the $2 \mathrm{~A}$ cell.

- in the second, instead of the temperatures we determined the fluxes from the bottom of the landfill to the aquifer able to reproduce the anomaly. The fluxes are equal to $2.80 \mathrm{~J} / \mathrm{m}^{2} \mathrm{~s}$ from $1 \mathrm{~A}$ cell and $0.94 \mathrm{~J} / \mathrm{m}^{2} \mathrm{~s}$ from $2 \mathrm{~A}$ cell.

Making a comparison between the simulated thermal fields (Fig. 4-5) and the experimental reconstruction (Fig. 2), the best results were achieved using constant thermal fluxes as boundary conditions.

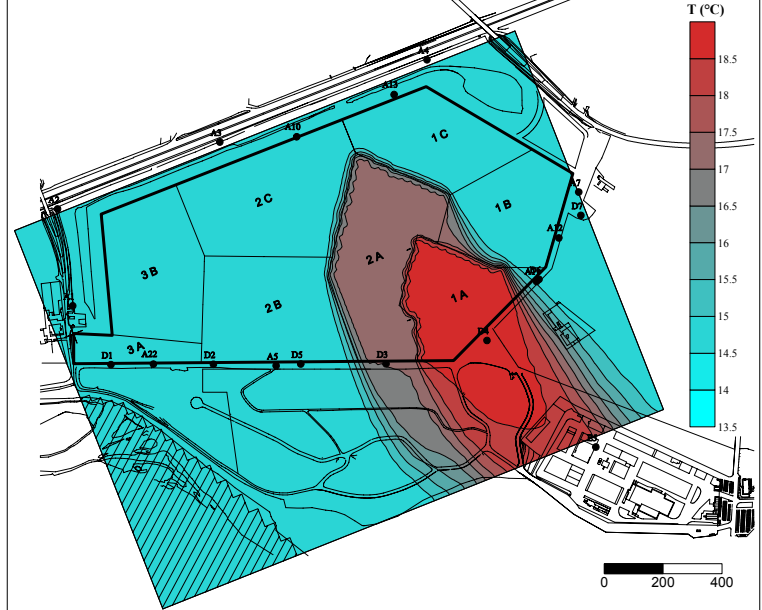

Fig. 4: Results of the first heat transport simulation (constant temperature).

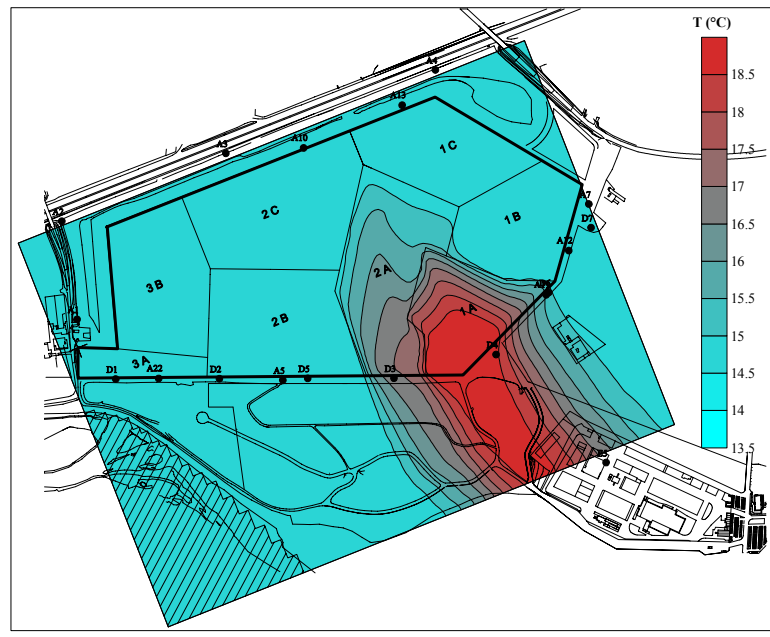

Fig. 5: Results of the second heat transport simulation (constant heat flux).

Table 2: Parameters of the heat transport simulation in the aquifer.

\begin{tabular}{|c|c|c|}
\hline Porosity & - & $n=0,20$ \\
\hline Reference background temp. & $\theta$ & $\operatorname{Tr}=14,5^{\circ} \mathrm{C}$ \\
\hline Solid phase density & $\mathrm{ML}^{-3}$ & $\rho^{s}=2,2 \mathrm{Kg} / \mathrm{m}^{3}$ \\
\hline Water density at $T_{r}$ & $\mathrm{ML}^{-3}$ & $\rho^{f}=999,24 \mathrm{~kg} / \mathrm{m}^{3}$ \\
\hline Water dynamic viscosity at $T_{r}$ & $\mathrm{ML}^{-1} \mathrm{~T}^{-1}$ & $\mu=1,1 \cdot 10^{-3} \mathrm{~Pa} \cdot \mathrm{s}$ \\
\hline Specific heat cap. of water & $\mathrm{L}^{2} \mathrm{~T}^{-2} \theta^{-1}$ & $c^{f}=4186 \mathrm{~J} / \mathrm{kg}^{\circ} \mathrm{C}$ \\
\hline Specific heat cap. of solid phase & $\mathrm{L}^{2} \mathrm{~T}^{-2} \theta^{-1}$ & $c^{s}=837,2 \mathrm{~J} / \mathrm{kg}^{\circ}{ }^{\circ} \mathrm{C}$ \\
\hline Long. thermodispersivity & $\mathrm{L}$ & $\beta_{L}=10 \mathrm{~m}$ \\
\hline Trans. thermodispersivity & $\mathrm{L}$ & $\beta_{T}=1 \mathrm{~m}$ \\
\hline Water heat capacity & $M L^{-1} T^{-2} \theta^{-1}$ & $\rho^{f} c^{f}=4183 \mathrm{~kJ} / \mathrm{m}^{3 .}{ }^{\circ} \mathrm{C}$ \\
\hline Solid phase heat capacity & $\mathrm{ML}^{-1} \mathrm{~T}^{-2} \theta^{-1}$ & $\rho^{s} c^{s}=1842 \mathrm{~kJ} / \mathrm{m}^{3 . \circ} \mathrm{C}$ \\
\hline Aquifer heat capacity & $\mathrm{ML}^{-1} \mathrm{~T}^{-2} \theta^{-1}$ & $\rho^{\prime} c^{\prime}=2427 \mathrm{~kJ} / \mathrm{m}^{3 .}{ }^{\circ} \mathrm{C}$ \\
\hline Retardation coefficient & - & $R_{T}=2,32$ \\
\hline Water heat conductivity & $\mathrm{MLT}^{-3} \theta^{-1}$ & $\lambda^{f}=0,54 \mathrm{~J} / \mathrm{ms}^{\circ} \mathrm{C}$ \\
\hline Solid phase heat conductivity & $\mathrm{MLT}^{-3} \theta^{-1}$ & $\lambda^{s}=2,09 \mathrm{~J} / \mathrm{ms}^{\circ} \mathrm{C}$ \\
\hline Aquifer heat conductivity & $\mathrm{MLT}^{-3} \theta^{-1}$ & $\lambda^{e}=1,67 \mathrm{~J} / \mathrm{ms}^{\circ} \mathrm{C}$ \\
\hline
\end{tabular}




\section{RESULTS AND DISCUSSION}

Some past measurements revealed a thermal anomaly in the aquifer downgradient $1 \mathrm{~A}$ and $2 \mathrm{~A}$ cells of the studied landfill. In order to give a better quantification of the problem a very detailed experimental analysis was conducted, both inside and outside the landfill: several temperature measurements were conducted inside the aquifer, in the waste, in the biogas and leachate wells. At the end of the investigation, no evidences were find to prove that temperature in $1 \mathrm{~A}$ or $2 \mathrm{~A}$ cell were higher than elsewhere.

The only reason that could explain the thermal anomaly in the groundwater is an high conductive or convective heat transport from the landfill towards the underlying aquifer. The hypothesis of an high conductive transport is supported by a poor natural and artificial impermeabilization under the two cells; moreover the rising of chemical conductivity during pumping could be an evidence of convective heat transport.

An heat transport model was developed in order to search the best heat boundary condition to reproduce the thermal anomaly in the aquifer. The simulation was performed using a contaminant transport model exploiting the analogy existing with heat transport models at low temperature gradients. The simulation permitted to single out the total power necessary to heat up the groundwater is $280 \mathrm{KW}$.

\section{REFERENCES}

1. El-Fadel M., A.N. Findikakis, J.O. Leckie, 1996. Numerical Modelling of generation and transport of gas and heat in sanitary landfills, I model formulation. Waste Management \& Research 1996, 14.

2. Zanetti M.C., L. Manna, G. Genon, 1997. Biogas production by means of thermal balances. Proceedings Sardinia 97.
3. Dach J., J. Jager, 1995. Prediction of gas and temperature with the disposal of pretreated residential waste, Proceedings Sardinia 95.

4. Lanini S., O. Aguilar, X. Lefebvre, G. Ballansat, 1997. Temperature increase in landfills during the aerobic period, Proceedings Sardinia 97.

5. Yoshida H., N. Tanaka, H. Hozumi, 1997. Theoretical Study on Heat Transport Phenomena in a Sanitary Landfill. Proceedings Sardinia 97.

6. Carslaw H.S., J.C. Jaeger, 1959. Conduction of heat in solids. Clarendons Press, London

7. Diersch H.-J.G., 2005. FEFLOW Reference manual. Wasy - Institute for Water Resources planning and System Research Ltd. Berlin. www.wasy.de.

8. Sethi R., 2000. Generazione e trasporto di calore da discariche di RSU agli acquiferi sottostanti. M. Sc. Thesis. Politecnico di Torino.

9. Zheng, C., Wang, P., 1998, "MT3DMS: A Modular Three-Dimensional Multispecies Transport Model for Simulation of Advection, Dispersion and Chemical Reactions of Contaminants in Groundwater Systems." University of Alabama. 